\title{
Estimating the Gait Speed of Older Adults in Smart Home Environments
}

\author{
Björn Friedrich $^{1}$ (I) Enno-Edzard Steen ${ }^{1} \cdot$ Sandra Hellmers ${ }^{1} \cdot$ Jürgen M. Bauer ${ }^{2} \cdot$ Andreas Hein $^{1}$
}

Received: 20 January 2021 / Accepted: 3 January 2022 / Published online: 12 January 2022

(c) The Author(s) 2022

\begin{abstract}
Mobility is one of the key performance indicators of the health condition of older adults. One important parameter is the gait speed. The mobility is usually assessed under the supervision of a professional by standardised geriatric assessments. Using sensors in smart home environments for continuous monitoring of the gait speed enables physicians to detect early stages of functional decline and to initiate appropriate interventions. This in combination with a floor plan smart home sensors were used to calculate the distance that a person walked in the apartment and the inertial measurement unit data for estimating the actual walking time. A Gaussian kernel density estimator was applied to the computed values and the maximum of the kernel density estimator was considered as the gait speed. The proposed method was evaluated on a real-world dataset and the estimations of the gait speed had a deviation smaller than $0.10 \frac{\mathrm{m}}{\mathrm{s}}$, which is smaller than the minimal clinically important difference, compared to a baseline from a standardised geriatrics assessment.
\end{abstract}

Keywords Ambient intelligence $\cdot$ Sensor fusion $\cdot$ Gait speed $\cdot$ Mobility assessment $\cdot$ Smart home $\cdot$ Older adults

\section{Introduction}

Self-determination is one of the basic psychological needs of human beings and is closely related to a good health condition, independence, and living a self-determined life [42]. Especially, older adults are prone to functional decline; hence, they are vulnerable to lose independence and to due to impairments they would also lose self-determination. For the health of older adults, it is important to regularly monitor their health condition. Detecting impending medical

Björn Friedrich

bjoern.friedrich@uni-oldenburg.de

Enno-Edzard Steen

enno-edzard.steen@uni-oldenburg.de

Sandra Hellmers

sandra.hellmers@uni-oldenburg.de

Jürgen M. Bauer

juergen.bauer@bethanien-heidelberg.de

Andreas Hein

andreas.hein@uni-oldenburg.de

1 Carl von Ossietzky University, Ammerländer Heerstraße 114-118, 26129 Oldenburg, Germany

2 Agaplesion Bethanien Hospital Heidelberg, Rohrbacher Straße 149, 69117 Heidelberg, Germany conditions and a decline in functionality at an early stage makes treatment more effective. Mobility and the gait speed in particular are considered as two of the best indicators for physical and mental health [31, 39, 44, 47]. A change in gait speed of a magnitude larger than $0.10 \frac{\mathrm{m}}{\mathrm{s}}$ is considered as minimal clinically important difference (M $\stackrel{s}{s}$ ID) $[10,47]$. For assessing the mobility, several geriatrics assessments are available. The Tinetti measures the mobility by assessing the two subcategories balance and gait [48]. The shortphysical-performance-battery (SPPB) is a composite of the three subcategories gait speed, standing balance, and sitto-stand performance [20]. However, the assessments must be performed under the supervision of a professional and attending physicians or physiotherapists frequently in short intervals exceeds the logistic capacity of physicians and physiotherapists. In Ref. [12], the most common assessments were identified. To identify the key factors, the scope of a comprehensive assessment was reduced using a data-driven approach: the principal component analysis (PCA) [37]. The PCA reduces the dimension of the assessment and extracts the essential components, which were measured within a comprehensive assessment.

A laboratory study with 79 participants aged 70 years at minimum included following tests [14, 22]: Instrumental Activities of Daily Living Scale (IADL) [27], Score of 
Frailty Criteria [43], Timed Up and Go (TUG) Test [40], SPPB [20], 6 Minute Walk Test (6MWT) [49], De Morton Mobility Index (DEMMI) [33], Stair Climb Power Test (SCPT) [5], and the Counter Movement Jump (CMJ) [41]. This battery of tests was needed to get a holistic view on the participants. The measured values obtained from these tests were examined using the PCA, which resulted in an extraction of three essential components. The first component included strength parameters like muscle mass, hand grip strength, and jump power. The second component held mobility parameters measured by the TUG or the walk test of the Frailty Index or SPPB. The third component was interpreted as balance factor, which included the balance tests of the DEMMI and SPPB. To reduce the scope of an assessment and obtain as much information as possible, all three essential components of the assessment should be covered by at least one test. Amongst these three components, the measurement of the mobility component is the easiest to transfer to a home setting and can be realised by measuring short walking distances through ambient or wearable sensors. As an intermediate step towards a home assessment covering all three components, this article will focus only on the measurement of functional performance in terms of mobility based on gait speeds for short distances. A sensor system provides objective and precise measurements and relieves the medical personnel. Since the sensors must be installed in the private homes of the patients, there is a high demand for privacy. Moreover, the patient should not feel like being monitored, because there is a difference between the self-selected gait speed and the maximum gait speed. In a test situation, people tend to give their best effort, whereas less effort is given in normal situations [18]. Regarding the gait speed, the meta-study in Ref. [38] found a difference of $0.29 \frac{\mathrm{m}}{\mathrm{s}}$ between the self-selected gait speed and the maximum gait speed. The average self-selected gait speed was $0.58 \frac{\mathrm{m}}{\mathrm{s}}$ and the average maximum gait speed was $0.89 \frac{\mathrm{m}}{\mathrm{s}}$. The results of a field study with older adults revealed a mean self-selected gait speed of $1.07 \frac{\mathrm{m}}{\mathrm{s}}$ and a mean maximum gait speed of $1.41 \frac{\mathrm{m}}{\mathrm{s}}$ with a difference of $0.34 \frac{\mathrm{m}}{\mathrm{s}}$ [32]. The selfselected gait speed and the maximum gait speed are dependent on several factors and so is the difference. It is difficult to draw general conclusions, but the self-selected gait speed and maximum gait speed are different. To address the difference in self-selected and maximum gait speed two filter settings, relaxed and strict, were used. To measure the gait speed the best approach is to use unobtrusive ambient sensors like motion sensors and wearable sensors like inertial measurement units (IMU). These systems are well accepted by the group of older adults as well [30]. These smart home sensors are also commonly used for telehealth monitoring and healthcare applications [28, 29].

In this article, a method for estimating the gait speed by fusing motion sensor and IMU data is introduced. "State of the Art" gives an overview of the state of the art, divided into wearable technologies and ambient technologies. In "Materials and Methods", the study for data acquisition, the data preparation, and the statistical model are described. All descriptions are accompanied by an example from the same study participant. In "Results", the results of the previously described method are shown and discussed in "Discussion". In "Conclusion and Future Work", conclusions are drawn and some prospects for future work are given.

\section{State of the Art}

Lately, the gait speed of older adults has been focused by a lot of researchers. Therefore, there are a many of approaches for measuring the gait speed using a variety of different sensors. Approaches using cameras are available as well. Even though the systems have a good accuracy, camera-based systems are not in favour for being used in private homes [19, $25,26,46]$. Therefore, approaches using wearable technologies or ambient sensors are considered and the camera-based approaches are excluded.

\section{Wearable Technologies}

It is not far to seek to the use of wearable sensors to estimate the gait speed. IMUs are small low-cost sensors for measuring acceleration. Research comparing the accuracy of IMUs to motion capture and gait analysis systems showed promising results and can be used interchangeably $[51,53]$.

In Ref. [9], non-linear features are extracted from IMU data. IMUs were mounted on the shank of the study participants. The captured data were used to extract the features which were fed to machine learning algorithms to estimate the gait speed. The root-mean-squared error in a laboratory study was $0.02 \frac{\mathrm{m}}{\mathrm{s}}$. The features are highly dependent on the rigid position of the IMU and incorporate the physical shape of the shank.

In Ref. [6], an IMU attached to the lower back was used to measure the gait speed amongst others. The algorithm has input parameters derived from the IMU sensor, vertical displacement, cadence, and step-time variability and participant specific information, age, sex, and foot length. A study in a controlled laboratory environment with 659 older adults participants was conducted to validate the algorithm. The results of the algorithm were compared to the values of a GAITRite walkway system. The root-mean-squared error was $0.07 \frac{\mathrm{m}}{\mathrm{s}}$. The algorithm depends on the fixed position of the IMU and the algorithm has not been evaluated in domestic environments.

In general, the IMU is rigidly attached to the human body and in a fixed position $[13,52]$. That is, prone to errors, if 
older adults are asked to always wear the sensor at the same position and the same orientation.

\section{Ambient Technologies}

Ambient technologies are useful to measure the behaviour of a person. The sensors are unobtrusive and can be installed in domestic environments. Thus, they have been facilitated to measure the gait parameters of older adults.

For assessing the gait speed without attaching sensors to the person, passive infrared sensors (PIR) are used. Those sensors are unobtrusive and privacy protecting. In Ref. [21] the capabilities of PIR sensors for measuring the gait speed were validated and a system of PIR sensors was installed in domestic environments for a field study with older adults. For calculating the gait speed, the distance between each pair of sensors must be known. In a laboratory study, the correlation of the gait speed measured by a GAITRite walkway system was highly correlated with the estimations of the PIR sensor system. The correlation was larger than 0.93 . The gait speed values in the field study were biased by the intention of the participant, e.g., a participant is choosing a higher gait speed for rushing to answer the telephone, than going to the TV to turn it on. Moreover, the self-selected gait speed was not considered.

In contrast to Ref. [21], the method proposed in Ref. [16] uses a floor plan for estimating the walked distance and not the distance between two sensors. The estimated gate speed deviated about $0.17 \frac{\mathrm{m}}{\mathrm{s}}$ from the average gait speed of the age set (20-42 years) of the participants in the laboratory study.

The system proposed in Ref. [8] was specifically designed for measuring the gait speed by PIR sensors. The system is unobtrusive and showed a good performance in a laboratory experiment. The difference to the ground truth was about $0.09 \frac{\mathrm{m}}{\mathrm{s}}$. Disadvantages are the installation in the apartment, because there must be a straight walking path of $1.20 \mathrm{~m}$ and the person must walk the path straight.

Besides the passive sensors, active infrared laser range finders were utilised to measure the gait speed in domestic environments. In Ref. [15], a laser range finder was used to measure the gait speed in a laboratory apartment. The difference of the measurements compared to the ground truth was $0.02 \frac{\mathrm{m}}{\mathrm{s}}$. However, a laser range finder is not considered as low-cost sensor.

Another approach is a system based on radio signals [24]. The system was able to accurately measure the gait speed in a controlled laboratory environment. The gait speed measured by the radio system was compared to the measurements of a VICON camera system with infrared markers. The deviation was smaller than $0.05 \frac{\mathrm{m}}{\mathrm{s}}$. The system has not been evaluated on real-world data.

The state-of-the-art analysis showed that either wearable sensors or ambient sensors are used. The results of both technologies are promising, but the systems have several restrictions like being rigidly attached to the body or special requirements to the apartment. The method of this research overcomes the disadvantages by fusion of IMU and motion sensor data and computing the magnitude of the IMU signal to mitigate the dependency on mounting location and orientation of the IMU.

\section{Materials and Methods}

The motion sensors in the apartments were used to determine the distance the patient walks, by dividing the apartment in several areas. When a patient leaves the first area, crosses the second, and enters the third, the information of the positions of the sensors was used to calculate the distance and the approximate time needed to cross the second area. For a rough approximation of the time, the time difference between the first sensor event of the motion sensor in the crossing area and the first motion sensor event of the motion sensor in the destination area was calculated. Using the motion sensor timestamps, the corresponding IMU data were selected. The IMU data give more information about the transition. Most important is the information whether the transition was straight or other activities were carried out. If the transition was not straight, then the walking time of the patient can be estimated by filtering the IMU data. With the knowledge about the transition and the distance, the gait speed can be estimated. Since the gait speed is just an estimation and people are not walking at the same pace every time, the probability distribution of the gait speed samples must be estimated. For estimating the probability distribution, a non-parametric statistics method is used, a kernel density estimation (KDE) with a Gaussian kernel. The maximum of the Gaussian KDE is considered as the correct gait speed. The proposed method has been evaluated on a realworld dataset. The data were collected during the OTAGO study conducted by the Carl von Ossietzky University of Oldenburg. As reference speed, the gait speed assessed by the SPPB under supervision of a professional is used. The difference of the reference gait speed and the estimated gait speed is less than $0.1 \frac{\mathrm{m}}{\mathrm{s}}$ and $0.30 \frac{\mathrm{m}}{\mathrm{s}}$ if the difference between the self-selected gait speed and the maximum gait speed found in Ref. [38]is considered.

\section{Data Acquisition}

The data have been collected in the OTAGO study conducted by the Carl von Ossietzky University of Oldenburg from 1st of July in 2014 to the 31 st of December 2015. The main purpose of the study was to analyse the effect of the OTAGO fall prevention exercise programme in (pre-)frail older adults $[7,36]$. The place of the study was the domestic 
environments of the 20 participants ( 17 female, 3 male). At the beginning of the study, the average age of the participants was 84.75 years (SD: 5.19 years). One inclusion criterion was the level of frailty. All participants must have been pre-frail or frail by the definition of Fried [17]. The average gait speed of the participants was $0.69 \frac{\mathrm{m}}{\mathrm{s}}$ (SD : $0.21 \frac{\mathrm{m}}{\mathrm{s}}$ ). The participants have been assigned to the intervention group, performing the OTAGO exercise programme, and the control group. During the field study, standardised geriatrics assessments, like Tinetti [48], SPPB, and TUG amongst others were performed and standardised questionnaires, like EQ-5D-5L [23], Mini Nutritional Assessment [50], and Instrumental Activities of Daily Living amongst others were answered on regular base. The different assessments and questionnaires were selected to get a holistic view of the participants. All assessments were performed in the domestic homes of the participants. One assessment set was performed at the beginning of the field study and the results were used as baseline. Then, every 4 weeks, another assessment date was planned. This lead to a total of 11 assessment dates and a total duration of the study of 40 weeks. Due to public holidays, family visits, and hospitalisation, the average time between two assessment dates was 31.3 days (SD: 5.3 days), and due to dropout, the average participation time was 36.5 weeks. From 16 out of the 20 participants, the results of 11 assessment dates are available. Two of the 20 participants deceased during the field study and two participants have ten results, because one assessment date had to be cancelled due to medical condition. On an average, 10.35 assessment dates are available per participant. During the study, wearable sensors and an ambient multi-component sensor system were used.

The wearable sensors were one IMU and one GPS receiver. The IMU type was a Shimmer3R by Shimmer [34] and the GPS receiver type was a Columbus V990 by Columbus [11]. On each assessment date, the IMU was given to the participant and he or she was asked to bring it any time. The IMU was supposed to be carried attached to a belt or in a pocket. After 1 week, the IMU was collected by an associate of the study. The GPS receiver was for outside usage. The participants were asked to bring the receiver every time they leave the apartment.

The ambient multi-component sensor system was comprised of several types of low-cost ambient sensors. For measuring the power consumption of appliances' power consumption, Plugwise Circle sensors were used. The sensors are designed to be put between the appliance and the power socket. The sensors are measuring the current energy consumption of the connected appliance and transfer the data wireless to a base station. For measuring the activity in the apartment, passive infrared motion sensors, contact sensors, and switches were used $[1,3,4]$. The motion sensors have been set up, so that their sensing spaces were not overlapping and covers as much space of the room and the walking paths as possible. Moreover, the sensors were arranged to detect a person as soon as he or she enters the room. The contact sensors were installed at the exterior doors. Next to the contact sensors at the exterior doors, a switch was installed. The participants were asked to turn the switch when another person enters or leaves the apartment. Both sensors were combined to detect entering and leaving people. One contact sensor was attached to the fridge for detecting fridge usage. To detect sleep times, a concussion sensor was placed between the slatted frame and the mattress in the bed of the participants [2]. In Fig. 1, the apartment of participant 20 is shown.

\section{Data Preparation}

There were several exclusion criteria on different scales. On participant scale, participants were excluded based on the following criterion:

1 If there were no or insufficient IMU data available for the participant: In some cases, participants did not use the IMU as they were supposed to or the timestamp of the IMU data could not be recovered, and sometimes, the data were lost, due to hardware failures.

On assessment date scale, there were the following exclusion criteria for excluding specific assessment dates:

2 If there were no or insufficient IMU data available for the time interval of the assessment: The IMUs were

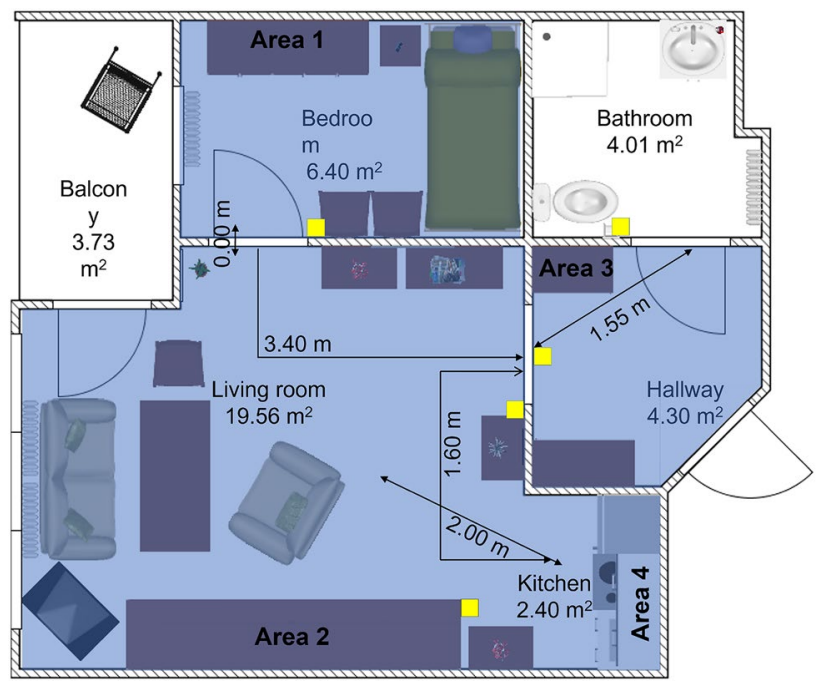

Fig. 1 The apartment of participant 20 in the OTAGO study. Three defined transition areas are depicted with a translucent shade and the ways are marked by an arrow. The squares are indicating the positions of the motion sensors (not true to scale) 
given to the participants at the beginning of each assessment. Some participants forgot to put it on the charging station for charging and uploading the data to the host computer.

3 If the assessment was not done in a correct manner: For a few assessments, the participants needed help from the physiotherapist to complete the assessments or were not able to complete it.

After exclusion, several filters were applied on different scales. The transitions between areas detected by the motion sensors were filtered. Two different filter settings were used. The relaxed filter settings allow a larger deviation from the assessment results. This is necessary, because the self-selected gait speed differs from the maximum gait speed measured by an assessment. The strict filter settings resulted in a deviation smaller than $0.10 \frac{\mathrm{m}}{\mathrm{s}}$ from the assessment results.

I The amount of the transitions must be larger than $50 \% / 25 \%$ (strict/relaxed) of the cumulative frequency of all transitions. The basic idea was that the estimation will be better using the most frequent transitions.

II The transition must satisfy the sensor graph of the apartment, e.g., a transition was filtered if there was no sensor event in an area the participant must cross to reach the destination area.

III For the full transition time, IMU data must be available.

IV Transitions with unreasonable gait speed were filtered. Transitions faster than $1.00-/ 1.20-$ m (strict/ relaxed) and slower or equal to $0.001 \frac{\mathrm{s}}{\mathrm{s}} / 0.00 \frac{\mathrm{m}}{\mathrm{s}}$ (strict/ relaxed) were filtered.

V Transitions in an interval of known sensor failures were filtered. Since the participants were living in the apartments, it happened that sensors were moved or dropped. Those sensors were readjusted on the next assessment date.

Figure 2 shows the frequency of the gait speeds measured by the motion sensors. The sensor graph mentioned in Filter II was made of vertices and edges. Each vertex represents one motion sensor. Two vertices were connected by an edge if and only if a path between the sensing spaces exists. The edge represents a path in the apartment, i.e., a transition between areas. Therefore, only adjacent vertices or areas were connected. The edges are bidirectional, because a path can be walked in both directions. The weighted sensor graph $G_{20}=\left(V_{20}, E_{20}, f_{20}\right)$ for the apartment shown in Fig. 1 has the following vertices and edges:

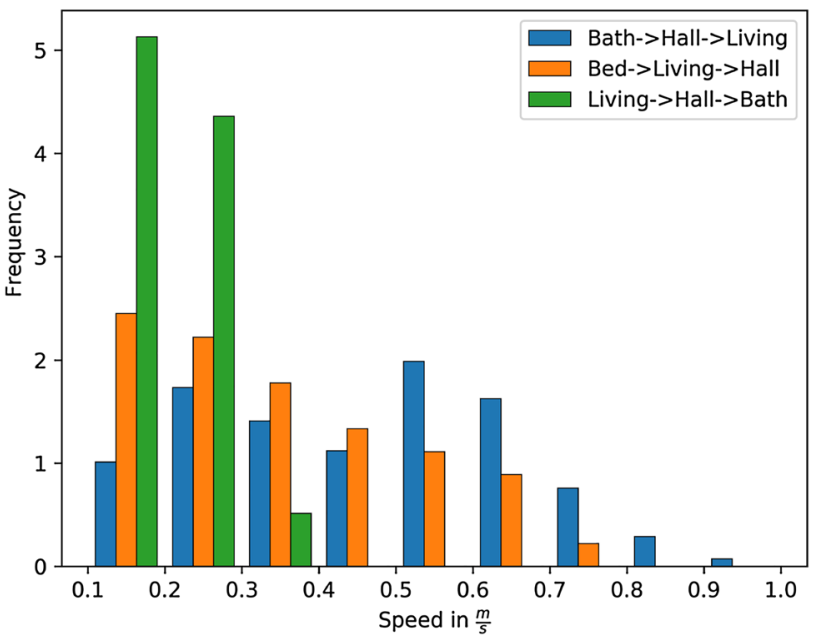

Fig. 2 The histogram shows how often different gait speeds of participant 20 were detected. The estimation is based on the distances between the areas and the motion sensor information. Invalid transitions were discarded

$V_{20}=\{$ Bed, Living, Kitchen, Hallway, Bath $\}$

$E_{20}=\{($ Bed, Living $)$, (Living, Kitchen $),($ Living, Hallway $)$,

(Hallway, Bath)\},

where $f_{20}$ is a function from $V_{20} \mapsto \mathbf{R}_{+}$. The function adds the weights to the edges. In case of the sensor graph, the weights are distances in metres between the sensing spaces. The distances were taken from the floor plans of the apartments. The function was piecewise defined as follows:

$f_{20}(e)=\left\{\begin{array}{l}0.00 e=(\text { Bed, Living) } \\ 2.00 e=\text { (Living, Kitchen) } \\ 3.40 e=\text { (Living, Hallway) } \\ 1.55 e=\text { (Hallway, Bath) } \\ 1.60 e=\text { (Hallway, Kitchen). }\end{array}\right.$

The edge (Bed, Living) has the weight 0 , because the motion sensors were detecting a person nearly at the same time when changing between the two rooms. Also notice that for the sake of uniqueness, the transition from the hallway to the kitchen was defined with one edge instead of two, even though the transition was via the living room. The transitions were defined by subgraphs. All subgraphs are satisfying the mathematical conditions of a path graph. There were five subgraphs of the graph $G_{20}$. The first one $G_{20}^{1}=\left(V_{20}^{1}, E_{20}^{1}, f_{20}^{1}\right)$ defines the transition that starts in the living room, crossing the hallway, and ends in the bathroom and the other way around. The sets $V_{20}^{1}$ and $E_{20}^{1}$ are

$V_{20}^{1}=\{$ Hallway, Bath $\}$

$E_{20}^{1}=\{($ Hallway, Bath $)\}$, 
with the weight function

$f_{20}^{1}(($ Hallway, Bath $))=1.55$.

The second one $G_{20}^{2}=\left(V_{20}^{2}, E_{20}^{2}, f_{20}^{2}\right)$ defines the transition starting in the bedroom, crossing the living room and finishing in the hallway and the other way around. The sets $V_{20}^{2}$ and $E_{20}^{2}$ are

$V_{20}^{2}=\{$ Living, Hallway $\}$

$E_{20}^{2}=\{($ Living, Hallway) $\}$,

with the weight function

$f_{20}^{2}(($ Living, Hallway $))=3.40$.

The third one $G_{20}^{3}=\left(V_{20}^{3}, E_{20}^{3}, f_{20}^{3}\right)$ defines a transition comprised of two edges. The transition starts in the bedroom, crossing the living room, the hallway, and ends in the bathroom and the other way around. The sets $V_{20}^{3}$ and $E_{20}^{3}$ are

$V_{20}^{3}=\{$ Living, Hallway, Bath $\}$

$E_{20}^{3}=\{($ Hallway, Bath), (Hallway, Living $)\}$,

with the weight function

$f_{20}^{3}(e)=\left\{\begin{array}{l}1.55 e=(\text { Hallway, Bath }) \\ 3.40 e=(\text { Hallway, Living }) .\end{array}\right.$

The fourth one $G_{20}^{4}=\left(V_{20}^{4}, E_{20}^{4}, f_{20}^{4}\right)$ defines a transition comprised of two edges as well. The transition starts in the bathroom, crossing the hallway, the living room, and ends in the kitchen. The living room is considered as part of the hallway, because another edge connecting the vertices living room and kitchen would violate the mathematical definition. The sets $V_{20}^{4}$ and $E_{20}^{4}$ are

$V_{20}^{4}=\{$ Hallway, Bath, Kitchen $\}$

$E_{20}^{4}=\{($ Hallway, Bath), (Hallway, Kitchen $)\}$,

with the weight function

$f_{20}^{4}(e)=\left\{\begin{array}{l}1.55 e=(\text { Hallway, Bath }) \\ 1.60 e=(\text { Hallway, Kitchen }) .\end{array}\right.$

The last subgraph $G_{20}^{5}=\left(V_{20}^{5}, E_{20}^{5}, f_{20}^{5}\right)$ defines the that transition starts in the bedroom, crossing the living room, and ends in the kitchen. The sets $V_{20}^{5}$ and $E_{20}^{5}$ are

$V_{20}^{5}=\{$ Living, Kitchen $\}$

$E_{20}^{5}=\{($ Living, Kitchen $)\}$,

with the weight function

$f_{20}^{4}(($ Living, Kitchen $)=2.00$
The detection of periods where multiple persons were in the apartment had two steps. In the first step, sensor events, indicating the number of people in the apartment changed, were searched. Those events depended on the layout of the apartment and opening the front door and opening the back door amongst others. Between two of those events, the number of people was assumed to be constant. If two events were found, all motion sensor data between them were analysed in the second detection step. The second step estimated whether nobody, one person, or more people were in the apartment. The estimation was 0 , if the frequency of motion sensor events dropped below an apartment-specific threshold, e.g., less than 1 event in $10 \mathrm{~min}$. For estimating the number of people, the graph and the sequence of sensor events were analysed. The violations of the graph were counted, and were the number of violations larger than a apartment-specific threshold, the presence of multiple persons was assumed. The sensor graph can be violated in two different manners. The first is the occurrence of two consecutive sensor events of sensors which are not adjacent. The second is the time difference of two consecutive sensor events of adjacent sensors. The distance between the sensing spaces of adjacent sensors was known and using the time difference between the events, the gait speed could be computed. If the gait speed was faster than a fixed threshold, a violation was counted. The gait speed threshold was set to $2 \frac{\mathrm{m}}{\mathrm{s}}$, because the average gait speed of the OTAGO cohort was $0.69 \frac{\mathrm{m}}{\mathrm{s}}$ and the fastest maximum gait speed was $1.41 \frac{\mathrm{m}}{\mathrm{s}}$. The threshold for the presence of multiple persons for each apartment was the ratio of sensor graph violations and total number of events in the considered period. If multiple persons were detected, the transitions were filtered. Based on the filtered set of transitions, the IMU data were loaded.

For preparing the fusion of the IMU data, the magnitude of the accelerometer and gyroscope values were computed before the next filters were applied. This was necessary to mitigate the unknown position and orientation of the IMU sensor. If the IMU's orientation was fixed you could assume that walking would always be visible in a specific direction, e.g., $\mathrm{x}$-axis' direction and detect walking directly observing the acceleration. Since the orientation was unknown the acceleration caused by walking could be on a different axis or distributed over all axis. Therefore, walking was indirectly measured by using the magnitude over all three axis. The magnitude was computed by the formula

$f(x, y, z)=\sqrt{x^{2}+y^{2}+z^{2}}$.

For the remaining transitions, the IMU data were filtered using the following two filters.

i All accelerometer values smaller or equal to $9.81 \frac{\mathrm{m}}{\mathrm{s}^{2}}$ were filtered. The assumption is that values equal or 
smaller to gravity belong to inactivity phases and were not walking time. Accounting measurement inaccuracy, the boundary is set to smaller.

ii All gyroscope values equal to $0.0 \frac{\mathrm{rad}}{\mathrm{s}}$ were filtered as well. The assumption was the same as for the accelerometer.

The Filters i and ii were conjugated by logical or. That means the sensor value was removed, if the accelerometer value was filtered or if the gyroscope value was filtered. Figure 3 shows the unfiltered IMU values of a transition of participant 20 from the bedroom, crossing the living room and arriving in the hallway. There is an inactivity phase $11.7 \mathrm{~s}$ and $15.7 \mathrm{~s}$ in the accelerometer and gyroscope values and between 16.7 and $18.7 \mathrm{~s}$ in the gyroscope values. The unfiltered values indicate a transition time of about $26.8 \mathrm{~s}$ complying a gait speed of $0.01 \frac{\mathrm{m}}{\mathrm{s}}$. The filtered values in Fig. 4 indicate $5.5 \mathrm{~s}$ as total walk time or a gait speed of $0.62 \frac{\mathrm{m}}{\mathrm{s}}$. The reference gait speed measured by the SPPB for this specific transition was $0.60 \frac{\mathrm{m}}{\mathrm{s}}$.

Figure 5 shows the relative frequency of the gait speed of the three most frequent transitions for participant 20 after applying the filters $\mathrm{I}-\mathrm{V}$ and $\mathrm{i}-\mathrm{ii}$. Besides the smaller amount of values, the ratio of the counts of different speeds is different to Fig. 2. There is a larger ration for speeds in the intervals from 0.40 to $0.50 \frac{\mathrm{m}}{\mathrm{s}}$ and to $0.60 \frac{\mathrm{m}}{\mathrm{s}}$. This reflects the average gait speed of participant 20 over all assessments of $0.55 \frac{\mathrm{m}}{\mathrm{s}}$.

Fig. 3 An example transition of participant 20 starting in the bedroom, crossing the living room, and ending in the hallway. The upper plot shows the unfiltered accelerometer values and the lower plot shows the unfiltered gyroscope values. All three axes are merged by Formula 1. The walking time is $26.8 \mathrm{~s}$. The IMU's measuring frequency is $101.5 \mathrm{~Hz}$
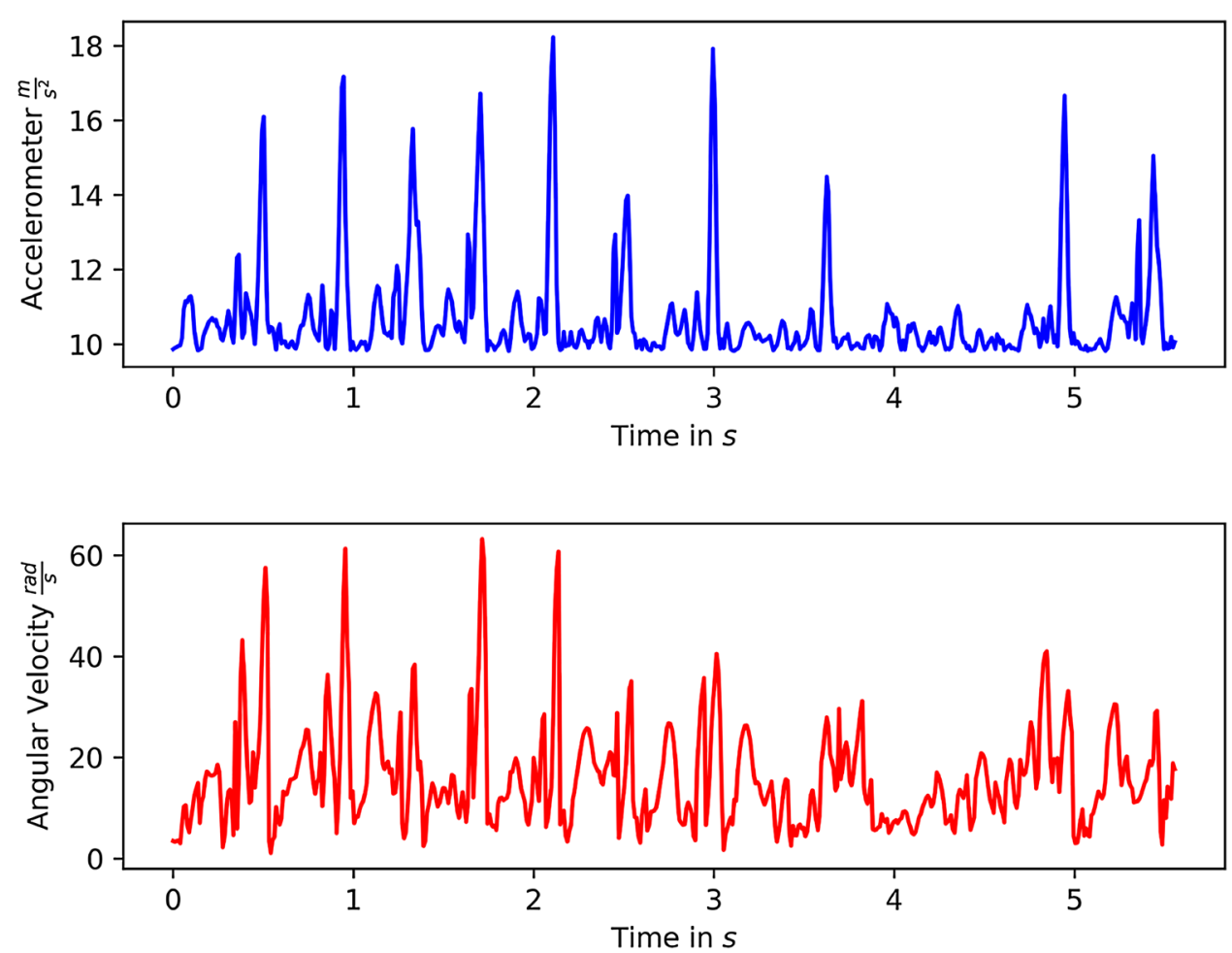

For estimating the specific gait speed corresponding to assessments, all filtered gait speed values inside an interval of 14 days prior and posterior to the assessment date were selected. Since the gait speed varied from transition to transition and was dependent on the intention as well, the values were likely drawn from a probability distribution. A KDE was applied to the gait speed values to estimate the underlying probability density function, approximate the gait speed and then the mean over all approximated speeds was used as the real gait speed.

In Table 1, the number of remaining values after applying each filter level is shown.

\section{Kernel Density Estimator}

The KDE is a function $\hat{f}_{n}: \mathbf{R} \mapsto \mathbf{R}_{+}$defined as follows:

$\hat{f}_{h}(x)=\frac{1}{n h} \sum_{i=1}^{n} K\left(\frac{x-x_{i}}{h}\right)$,

where $K$ is the kernel function, $h$ the bandwidth, and $x_{i}$ a sample from a set of samples $\left\{x_{1}, \ldots, x_{n}\right\}$ drawn from independent and identically univariate distributed density functions $f$. Equation (2) has two parameters to choose. The first one is the kernel $K$ and the second one is the bandwidth. Based on our previous research [22], the Gaussian kernel is used in this research. Table 3 shows a comparison of the performance to simply using the mean gait speed and the 
Fig. 4 An example transition of participant 20 starting in the bedroom, crossing the living room, and ending in the hallway. The upper plot shows the filtered accelerometer values and the lower plot the filtered gyroscope values. All three axis are merged by Formula 1. The walking time is $5.5 \mathrm{~s}$. The IMU's measuring frequency is $101.5 \mathrm{~Hz}$
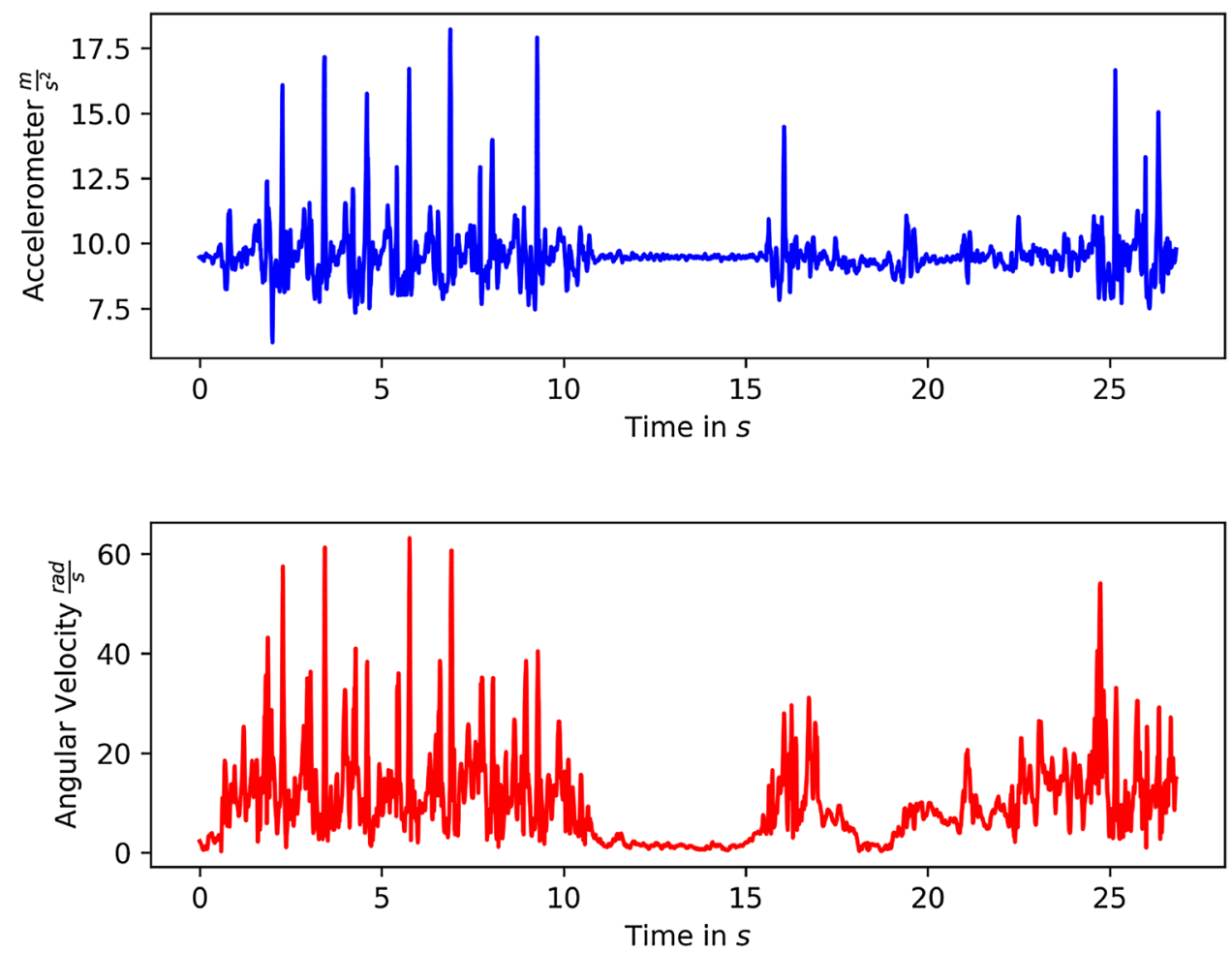

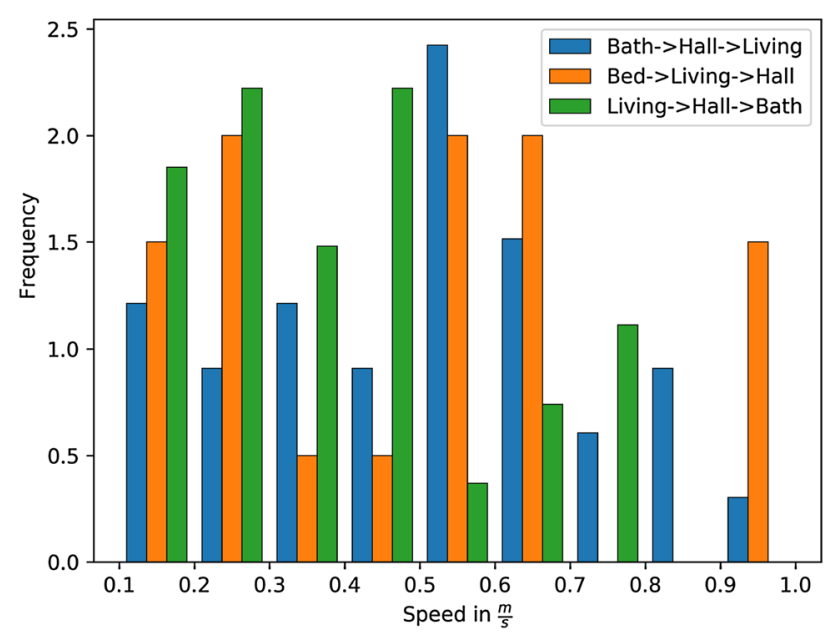

Fig. 5 The gait speed calculated based on the sensor fusion of the motion sensors and the IMU after filtering

Tophat kernel. A Gaussian kernel is defined by the following equation:

$K(x):=\frac{1}{\sqrt{2 \pi}} e^{-\frac{1}{2} x^{2}}$.

The bandwidth has a strong influence of the quality of the density estimation. Dependent on the sample size and the bandwidth, the kernel density estimator is almost sure
Table 1 The remaining number of values after applying each set of filters strictly

\begin{tabular}{lrrllc}
\hline & Raw & Filter 1 & Filters 2, 3 & Filters I-V & Filters i, ii \\
\hline Participants & 20 & 13 & 12 & $11(12)$ & $9(12)$ \\
$\begin{array}{l}\text { Assessment } \\
\text { dates }\end{array}$ & 201 & 125 & 47 & $25(33)$ & $17(33)$ \\
\begin{tabular}{l} 
Transitions \\
\hline
\end{tabular} & 376 & 208 & 42 & $35(35)$ & $35(35)$ \\
\hline
\end{tabular}

The largest loss of data occurs when applying Filter 1, because it filters participants and one participant has several assessment dates and even more transitions. The number of transitions is the number of different transitions. The values in parenthesis are the values if the filters are relaxed

uniform converging to the unknown distribution [35]. The bandwidth can be chosen to fit the current needs. The only condition is it must be greater 0 . The bandwidth controls the smoothness of the kernel. For the extreme case $h \rightarrow 0$, the kernel is not smooth and shows artifacts. For the other extreme case $h \rightarrow \infty$, the kernel is absolutely smooth and equals the distribution of the kernel centered around the mean of the samples $x_{i}$. For the proposed method, the bandwidth is chosen according to a rule of thumb proposed by Silverman in Ref. [45]. The bandwidth according to Silverman's rule of thumb is computed as follows:

$h=0.9 \times \min \left(\hat{\sigma}, \frac{\mathrm{IQR}}{1.34}\right) \times n^{-\frac{1}{5}}$, 
Fig. 6 The three histograms for the transitions in Fig. 5 of participant 20. The transitions are beginning in the bathroom, crossing the hallway, ending in the living room, and beginning in the living room, crossing the hallway, ending in the bathroom and beginning in the bedroom, crossing the living room, and ending in the hallway and the maxima of the KDEs are $0.6 \frac{\mathrm{m}}{\mathrm{s}}$, $0.1 \frac{\mathrm{m}}{\mathrm{s}}, 0.5 \frac{\mathrm{m}}{\mathrm{s}}$, respectively
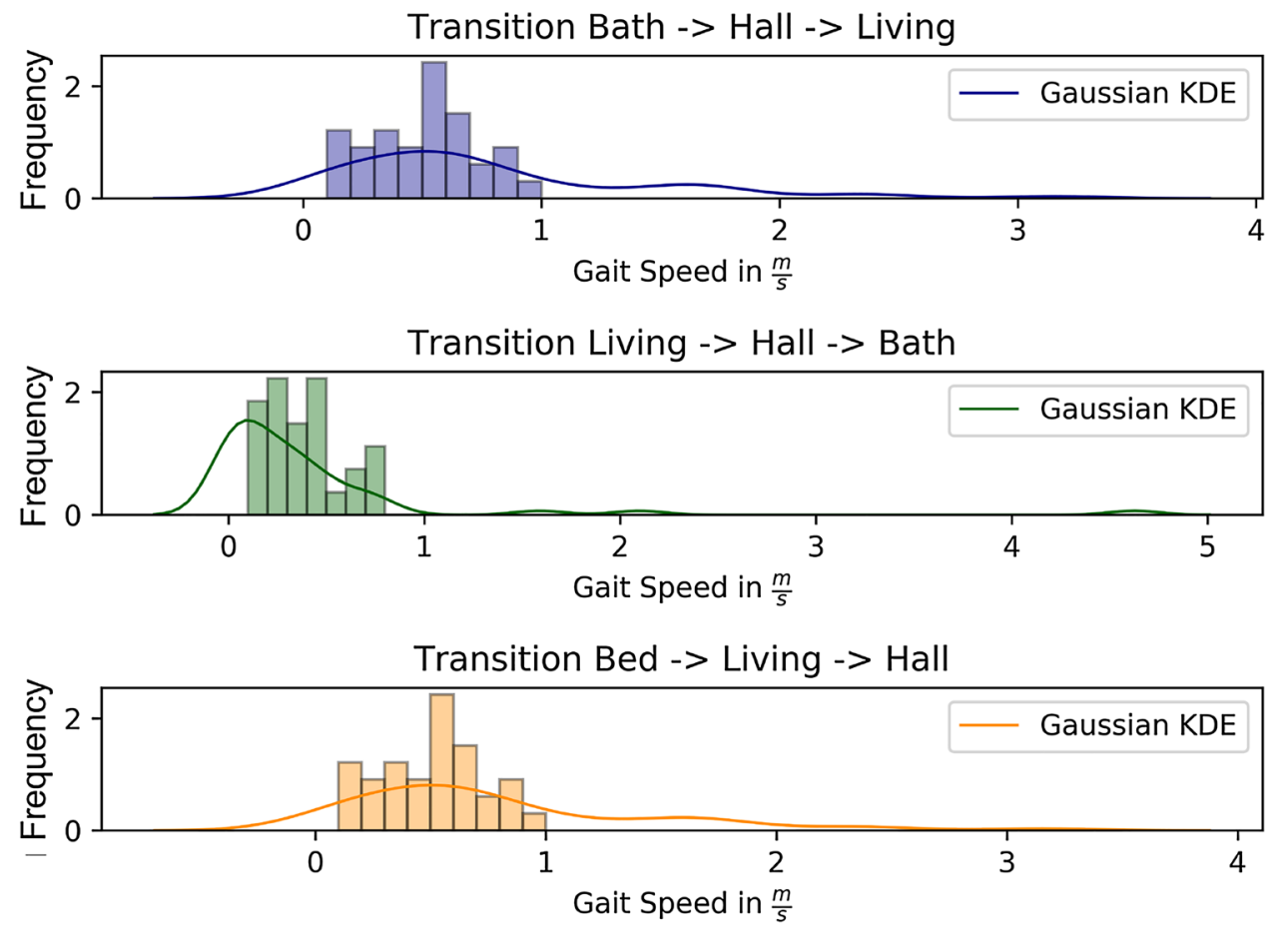

Table 2 An example of the computation of the strict filtered transitions for the strict filtered assessments for participant 20

\begin{tabular}{llllc}
\hline Transition & Distance $[\mathrm{m}]$ & Speed $_{\text {base }}\left[\frac{\mathrm{m}}{\mathrm{s}}\right]$ & Speed $_{\text {est }}\left[\frac{\mathrm{m}}{\mathrm{s}}\right]$ & Difference $\left[\frac{\mathrm{m}}{\mathrm{s}}\right]$ \\
\hline Bed $\rightarrow$ Living $\rightarrow$ Hall & 3.40 & 0.60 & 0.68 & 0.08 \\
Bed $\rightarrow$ Living $\rightarrow$ Hall & 3.40 & 0.56 & 0.49 & -0.07 \\
Bed $\rightarrow$ Living $\rightarrow$ Hall & 3.40 & 0.47 & 0.24 & -0.23 \\
Bed $\rightarrow$ Living $\rightarrow$ Hall & 3.40 & 0.58 & 0.68 & 0.10 \\
Living $\rightarrow$ Hall $\rightarrow$ Bath & 2.55 & 0.60 & 0.51 & -0.09 \\
Living $\rightarrow$ Hall $\rightarrow$ Bath & 2.55 & 0.56 & 0.51 & 0.05 \\
Living $\rightarrow$ Hall $\rightarrow$ Bath & 2.55 & 0.47 & 0.51 & 0.04 \\
Living $\rightarrow$ Hall $\rightarrow$ Bath & 2.55 & 0.58 & 0.64 & 0.06 \\
Bath $\rightarrow$ Living $\rightarrow$ Hall & 2.55 & 0.60 & 0.85 & 0.24 \\
\hline
\end{tabular}

The distance is the direct distance needed to complete the transition
Table 3 The comparison of the Gaussian kernel to the baseline, i.e., mean gait speed, and the Tophat kernel

\begin{tabular}{lll}
\hline Kernel & Mean error & $\begin{array}{l}\text { Error } \\
\text { standard } \\
\text { deviation }\end{array}$ \\
\hline Mean gait speed & -3.30 & 4.96 \\
Tophat & 0.15 & 0.31 \\
Gaussian & 0.14 & 0.27 \\
\hline
\end{tabular}

The Gaussian kernel shows the lowest mean error and deviation from the speed measured in the assessments on all participants. All values are in $\frac{\mathrm{m}}{\mathrm{s}}$

where $\hat{\sigma}$ is the standard deviation of the samples, $n$ the sample size, and IQR the interquartile range.
Plugging in Eqs. (4) and (3) in (2) leads to the final mathematical model.

Figure 6 shows the Gaussian KDE applied to the transitions of participant 20 for one assessment date. The ground truth gait speed measured by the SPPB was $0.60 \frac{\mathrm{m}}{\mathrm{s}}$ and the mean of the maxima of the KDEs for the three transitions are $0.60 \frac{\mathrm{m}}{\mathrm{s}}, 0.10 \frac{\mathrm{m}}{\mathrm{s}}$, and $0.50 \frac{\mathrm{m}}{\mathrm{s}}$, respectively. The estimated gait speed is $0.55 \frac{\mathrm{m}}{\mathrm{s}}$ which is $0.05 \frac{\mathrm{m}}{\mathrm{s}}$ slower than the ground truth. Table 2 shows the baseline values and the estimated values for all considered transitions and assessment dates of participant 20 . 


\section{Results}

The procedure described beforehand was applied with two different filter settings. The first setting was as strict as previously described and the second setting took the difference of the self-selected gait speed and maximum gait speed of $0.29 \stackrel{\mathrm{m}}{-}$ found in [38] into account. To achieve this, the Filters $\mathrm{I}$ and IV were relaxed. The numbers in bold font are indicating the best and worst over- and underestimations.

In Table 4, the results for the strict filter settings are shown. The mean of the maximum gait speed of the participants was $0.76 \frac{\mathrm{m}}{\mathrm{s}}\left( \pm 0.20 \frac{\mathrm{m}}{\mathrm{s}} \mathrm{SD}\right)$ and the difference is of an average of $0.04 \frac{\mathrm{m}}{\mathrm{s}}$. The largest overestimation of the gait speed is $0.09 \frac{\mathrm{m}}{\mathrm{s}}$ and the largest underestimation is $-0.09 \frac{\mathrm{m}}{\mathrm{s}}$. The smallest overestimation of the gait speed is $0.03 \frac{\mathrm{m}}{\mathrm{s}}$ and the smallest underestimation is $-0.01 \frac{\mathrm{m}}{\mathrm{s}}$. The fastest gait speed estimation is $0.92 \frac{\mathrm{m}}{\mathrm{s}}$ and the slowest is $0.25 \frac{\mathrm{m}}{\mathrm{s}}$. There is no estimation that exactly meets the baseline. Regarding the assessments, the slowest gait speed is $0.34 \frac{\mathrm{m}}{\mathrm{s}}$ with a difference of $-0.09 \frac{\mathrm{m}}{\mathrm{s}}$ to the estimated gait speed of $0.25 \frac{\mathrm{m}}{\mathrm{s}}$ and the fastest gait speed is $1.00 \frac{\mathrm{m}}{\mathrm{s}}$ with a difference of $-0.08 \frac{\mathrm{m}}{\mathrm{s}}$ to the estimated gait speed of $0.92 \frac{\mathrm{m}}{\mathrm{s}}$.

In Table 5, the results for the relaxed filter settings are shown. The mean of the gait speed is $0.64 \frac{\mathrm{m}}{\mathrm{s}}\left( \pm 0.18 \frac{\mathrm{m}}{\mathrm{s}} \mathrm{SD}\right)$

Table 4 The results of the strict filter settings of the algorithm

\begin{tabular}{llll}
\hline Speed $_{\text {base }}\left[\frac{\mathrm{m}}{\mathrm{s}}\right]$ & Speed $_{\text {est }}\left[\frac{\mathrm{m}}{\mathrm{s}}\right]$ & Difference $\left[\frac{\mathrm{m}}{\mathrm{s}}\right]$ & ID \\
\hline 0.60 & 0.59 & $-\mathbf{0 . 0 1}$ & 20 \\
0.55 & 0.50 & -0.05 & 20 \\
0.47 & 0.38 & $-\mathbf{0 . 0 9}$ & 20 \\
0.58 & 0.66 & 0.08 & 20 \\
0.40 & 0.37 & -0.03 & 19 \\
0.40 & 0.34 & -0.06 & 18 \\
0.52 & 0.56 & 0.04 & 18 \\
0.58 & 0.67 & $\mathbf{0 . 0 9}$ & 18 \\
$\mathbf{0 . 3 4}$ & $\mathbf{0 . 2 5}$ & $-\mathbf{0 . 0 9}$ & 16 \\
0.89 & $\mathbf{0 . 9 2}$ & $\mathbf{0 . 0 3}$ & 15 \\
$\mathbf{1 . 0 0}$ & $\mathbf{0 . 9 2}$ & $-\mathbf{0 . 0 8}$ & 15 \\
0.93 & $\mathbf{0 . 9 2}$ & $-\mathbf{0 . 0 1}$ & 15 \\
0.66 & 0.57 & -0.09 & 14 \\
0.64 & 0.58 & -0.06 & 14 \\
0.78 & 0.62 & -0.04 & 13 \\
0.70 & 0.61 & -0.09 & 13 \\
0.69 & 0.67 & -0.02 & 7 \\
0.80 & 0.76 & -0.04 & \\
\hline
\end{tabular}

The baseline was measured during an SPPB assessment supervised by a professional. In the second column, the values estimated by the algorithm are shown, and in the last column, the absolute value of the difference are shown. One row represents one assessment date
Table 5 The results for the relaxed filter settings of the algorithm

\begin{tabular}{|c|c|c|c|}
\hline Speed $_{\text {base }}\left[\frac{\mathrm{m}}{\mathrm{s}}\right]$ & Speed $_{\text {est }}\left[\frac{\mathrm{m}}{\mathrm{s}}\right]$ & Difference $\left[\frac{\mathrm{m}}{\mathrm{s}}\right]$ & ID \\
\hline 0.60 & 0.59 & -0.01 & 20 \\
\hline 0.55 & 0.50 & -0.05 & 20 \\
\hline 0.47 & 0.38 & -0.09 & 20 \\
\hline 0.58 & 0.66 & 0.08 & 20 \\
\hline 0.40 & 0.37 & -0.03 & 19 \\
\hline 0.40 & 0.34 & -0.06 & 18 \\
\hline 0.52 & 0.56 & 0.04 & 18 \\
\hline 0.65 & 0.43 & -0.22 & 18 \\
\hline 0.58 & 0.67 & 0.09 & 17 \\
\hline 0.34 & 0.25 & -0.09 & 16 \\
\hline 0.89 & 0.92 & 0.03 & 15 \\
\hline 1.00 & 0.92 & -0.08 & 15 \\
\hline 0.98 & 0.77 & -0.21 & 15 \\
\hline 0.93 & 0.92 & -0.01 & 15 \\
\hline 0.94 & 0.77 & -0.17 & 15 \\
\hline 0.90 & 0.60 & $-\mathbf{0 . 3 0}$ & 14 \\
\hline 0.85 & 0.56 & -0.29 & 14 \\
\hline 0.66 & 0.57 & -0.09 & 13 \\
\hline 0.64 & 0.58 & -0.06 & 13 \\
\hline 0.74 & 0.97 & 0.23 & 13 \\
\hline 0.87 & 0.63 & -0.24 & 13 \\
\hline 0.78 & 0.62 & -0.04 & 12 \\
\hline 0.70 & 0.61 & -0.09 & 12 \\
\hline 0.69 & 0.67 & -0.02 & 9 \\
\hline 0.77 & 0.53 & -0.24 & 9 \\
\hline 0.74 & 1.00 & 0.26 & 9 \\
\hline 0.92 & 0.69 & -0.23 & 7 \\
\hline 0.80 & 0.76 & -0.04 & 7 \\
\hline 1.01 & 0.82 & -0.19 & 5 \\
\hline 0.98 & 0.79 & -0.19 & 5 \\
\hline 1.03 & 0.83 & -0.20 & 5 \\
\hline 1.01 & 0.73 & -0.28 & 5 \\
\hline 1.08 & 0.82 & -0.26 & 5 \\
\hline
\end{tabular}

The baseline was measured during an SPPB assessment supervised by a professional. In the second column, the values estimated by the algorithm are shown, and in the last column, the absolute value of the difference is shown. One row represents one assessment date. The unit of all values is $\frac{\mathrm{m}}{\mathrm{s}}$

and the difference to the assessments are of an average of $0.09 \mathrm{~m}$. The largest overestimation of the gait speed is $0.26 \frac{\mathrm{m}}{\mathrm{s}}$ and the largest underestimation is $-0.30 \frac{\mathrm{m}}{\mathrm{s}}$. The smallest overestimation of the gait speed is $0.03 \frac{\mathrm{m}}{\mathrm{s}}$ and the smallest underestimation is $-0.01 \frac{\mathrm{m}}{\mathrm{s}}$. The fastest gait speed estimation is $1.00 \frac{\mathrm{m}}{\mathrm{s}}$ and the slowest is $0.25 \frac{\mathrm{m}}{\mathrm{s}}$. There is no estimation that exactly meets the baseline. Regarding the assessments, the slowest gait speed is $0.34 \frac{\mathrm{m}}{\mathrm{s}}$ with a difference of $-0.09 \frac{\mathrm{m}}{\mathrm{s}}$ to the estimated gait speed of $0.25 \frac{\mathrm{m}}{\mathrm{s}}$ and 
the fastest gait speed is $1.08 \frac{\mathrm{m}}{\mathrm{s}}$ with a difference of $-0.26 \frac{\mathrm{m}}{\mathrm{s}}$ to the estimated gait speed of $0.82 \frac{\mathrm{m}}{\mathrm{s}}$.

The number of strictly filtered assessments is 18 and the number of relaxed filtered assessments is 33 . The slowest assessment gait speed appears in both tables and for the strictly filtered values it also belongs to the greatest underestimation. The smallest overestimation and the smallest underestimation are appearing in both tables as well. As expected, the largest overestimation and the largest underestimation are different in both tables.

The results of a basic statistical analysis of the differences are shown in Table 6. The mean and SD of the strict filter settings are smaller than the mean and SD of the relaxed filtered values. The strict filtered mean and SD are about one-half to one-third of the filtered mean an SD. The percentage of overestimations and underestimations does not significantly differ.

The gait speeds measured by the geriatric assessment are not normally distributed and neither the estimated values. The values of the Kolmogorov-Smirnov goodness-of-fit test's are 0.61 with a critical value of 0.27 and 0.60 with a critical value of 0.392 , respectively. For analysing the correlation Spearman's Rho must be used, since the data are not normal distributed. The results for the correlation analysis of the baseline values and the differences are for the relaxed filtered values are $\rho=-0.50(p<0.003)$ and the results for the strict filtered values are $\rho=0.09(p<0.695)$. Table 7 gives an overview over the statistic results.

Table 6 The results of the statistical analysis of the differences

\begin{tabular}{|c|c|c|c|}
\hline & $\begin{array}{l}\text { Overestimation } \\
(\text { mean, SD) }\end{array}\left[\frac{\pi}{\mathrm{s}}\right]$ & $\left.\begin{array}{l}\text { Underestimation } \\
(\text { mean, SD) } \\
\mathrm{s}\end{array}\right]$ & Percentage \\
\hline Strict filtered & $0.06,0.03$ & $-0.05,0.03$ & $22.22 \%, 77.78 \%$ \\
\hline Relaxed filtered & $0.12,0.09$ & $-0.14,0.10$ & $18.18 \%, 81.82 \%$ \\
\hline
\end{tabular}

The first value in the column percentage is the percentage of overestimations and the second value is the percentage of underestimations. The values in the remaining columns are $\frac{\mathrm{m}}{\mathrm{s}}$

\section{Discussion}

It appears that the number of participants shrank about $65 \%$ after passing the filter pipeline, only $40 \%$, if the filter settings were relaxed. For the number of assessment dates, about $8.5 \%$ and about $16.5 \%$ were left and about $9.3 \%$ of the different transitions were left. The data were recorded in a real-world study and the quality of the raw data is very low. Moreover, the motion sensor system was not designed for measuring gait speed and the overall quality of the data was dependent on the participant as well. Especially, the IMU data, because the participant was responsible for wearing the IMU, transferring the data, and charging it. This led to the greatest loss of data in the Filters I, II, and III. The remaining transitions after applying the Filter I were not complementary, i.e., the reverse transition might be filtered, but the forward transition was still present. That can partly be seen in Table 2 . The transition starting in the bedroom and ending in the hallway was present, but the reverse transition from the hallway to the bedroom had only one value for that assessment date. This occurred due to the positioning of the sensors. The sensors could not measure both directions with the same accuracy, and hence, one of the complementary transitions was filtered.

In coherence to the findings about the self-selected gait speed and the maximum gait speed, the algorithm was underestimating the gait speed in the majority of cases $(77.78 \%$, $81.82 \%)$. Relaxing the Filters I and IV led to a larger dataset whose values were still accurate considering the difference of $0.29 \frac{\mathrm{m}}{\mathrm{s}}$ between the self-selected gait speed and the maximum gait speed. However, it is not possible to identify whether the difference was because of the data quality or the difference between the self-selected gait speed and the maximum gait speed. The values found in Ref. [38] are different to the values of the OTAGO cohort and cannot be directly compared. The average gait speed of the OTAGO cohort is $0.69 \frac{\mathrm{m}}{\mathrm{s}}$ and $0.20 \frac{\mathrm{m}}{\mathrm{s}}$ slower than $0.89 \frac{\mathrm{m}}{\mathrm{s}}$ and the SD is $0.21 \frac{\mathrm{m}}{\mathrm{s}}$ and $0.14 \frac{\mathrm{m}}{\mathrm{s}}$ smaller. The average maximum gait speed of the cohort is significantly slower than the average maximum gait speed found in Ref. [38] and only the half of the average maximum gait speed found in Ref. [32].

The correlation analysis revealed that the reference gait speed was not correlated with the difference to the gait speed estimation. Therefore, the proposed method is working independent of the gait speed.
Table 7 The results of the statistical analysis

\begin{tabular}{llllr}
\hline & Mean $\left[\frac{\mathrm{m}}{\mathrm{s}}\right]$ & $\mathrm{SD}\left[\frac{\mathrm{m}}{\mathrm{s}}\right]$ & KS (critical value) & Spearman's Rho \\
\hline Strict filtered & 0.76 & 0.20 & $0.63(>0.392)$ & $0.09(p<0.695)$ \\
Relaxed filtered & 0.64 & 0.18 & $0.63(>0.277)$ & $-0.50(p<0.003)$ \\
\hline
\end{tabular}




\section{Conclusion and Future Work}

In this article, a method for measuring the gait speed in smart homes was introduced. The method neither imposes constraints on older adults nor requires major building refurbishments. Moreover, the used sensors are respecting the privacy of the dweller and they are not expensive. The evaluation on the real-world dataset collected during the OTAGO study proved the quality and usability of the method. The gait speed could be estimated with a deviation of less than $0.10 \frac{\mathrm{m}}{\mathrm{s}}$ compared to a gold standard geriatrics assessment and less than $0.30 \frac{\mathrm{m}}{\mathrm{s}}$ applying less strict filters to take the difference between the self-selected gait speed and the maximum gait speed into account. The acquired accuracy is sufficient to detect significant changes in gait speed, and the continuous monitoring of the gait speed enables doctors and professionals to examine the patient at an early stage of an impending medical condition.

However, a lot of filters had to be applied to the data, and the difference of the self-selected gait speed and the maximum gait speed is not considered in a sophisticated manner. To overcome those two points, there are two possible next steps, i.e., extracting more information from the IMU data and to figure out what is the most feasible difference between the self-selected gait speed and the maximum gait speed of the OTAGO cohort.

By analysing the IMU data in a more detailed way, information about the movement of the person could be derived. If information about the movement is available, actions like opening a door can be identified. Using those information, the approximation of the walking time becomes more accurate and so does the approximation of the gait speed.

To face the problem of the difference between the selfselected gait speed and the maximum gait speed, a systematic review is the most promising approach. The OTAGO study took place in 2014 and 2015, and the participants are not available for further measurements anymore. Moreover, finding a cohort similar to the previous one is very difficult. The systematic review should focus on cohorts as similar as possible to the OTAGO cohort. This gives deeper insights of the self-selected gait speed, the maximum gait speed, and the factors both are depending on.

Acknowledgements We acknowledge Bianca Sahlmann (University of Oldenburg) and Lena Elgert (Peter L. Reichertz Institute, Hannover) for supervising the assessments. The OTAGO study has been funded by an internal funding of the Carl von Ossietzky University of Oldenburg.

Author Contributions Conceptualization: $\mathrm{BF}$ and E-ES and SH; methodology: BF and E-ES and SH; software: BF; validation: $\mathrm{BF}$; formal analysis: $\mathrm{BF}$ and $\mathrm{E}-\mathrm{ES}$; investigation: $\mathrm{BF}$ and $\mathrm{SH}$; resources: JMB and $\mathrm{AH}$; data curation: $\mathrm{BF}$ and E-ES; writing - original draft preparation: $\mathrm{BF}$ and E-ES and SH; writing-review and editing: JMB and $\mathrm{AH}$; visualization: $\mathrm{BF}$; supervision: $\mathrm{AH}$; project administration: $\mathrm{AH}$; funding acquisition: JMB and $\mathrm{AH}$
Funding Open Access funding enabled and organized by Projekt DEAL. This research received no external funding.

Data Availability The data are not publicly available due to privacy concerns.

Code Availability Custom code was used for this research.

\section{Declarations}

Conflict of interest The authors declare that they have no conflict of interest.

Ethical approval The OTAGO study was conducted according to the guidelines of the Declaration of Helsinki, and approved by the Institutional Review Board of the Carl von Ossietzky University (protocol code: Drs.27/2014, date of approval: 30.04.2014).

Consent to participate Informed consent was obtained from all subjects involved in the study.

Open Access This article is licensed under a Creative Commons Attribution 4.0 International License, which permits use, sharing, adaptation, distribution and reproduction in any medium or format, as long as you give appropriate credit to the original author(s) and the source, provide a link to the Creative Commons licence, and indicate if changes were made. The images or other third party material in this article are included in the article's Creative Commons licence, unless indicated otherwise in a credit line to the material. If material is not included in the article's Creative Commons licence and your intended use is not permitted by statutory regulation or exceeds the permitted use, you will need to obtain permission directly from the copyright holder. To view a copy of this licence, visit http://creativecommons.org/licenses/by/4.0/.

\section{References}

1. AG EE. 2-Kanal-Funk-Bewegungsmelder Für Außeneinsatz FS20 PIRA Bedienungsanleitung. 2006. https://files2.elv.com/public/ 06/0668/066818/-Internet/66818_um.pdf. (German).

2. AG EE. 2-Kanal-Funk-Erschütterungssensor FS20 ES1 Bedienungsanleitung. 2007. http://www.ezcontrol.de/Bedienungsanlei tung/ELV/85-800_FS20ES1_d_UM.pdf. (German).

3. AG EE. 2-/4-Kanal Aufputz-Wandsender FS20 S4A-2. 2009. https://files2.elv.com/public/07/0736/073623/Internet/-73623_ um.pdf. (German).

4. AG EE. 2-Kanal-Funk-Tür-/Fenster-Kontakt FS20 TFK Bedienungsanleitung. 2009. https://files.elv.com/service/manuals/ FS-20TFK/FS20TFK_UM_G_050727.pdf. (German).

5. Bean JF, Kiely DK, LaRose S, Alian J, Frontera WR. Is stair climb power a clinically relevant measure of leg power impairments in at-risk older adults? Arch Phys Med Rehabil. 2007;88(5):604-9. https://doi.org/10.1016/j.apmr.2007.02.004.

6. Byun S, Lee HJ, Han JW, Kim JS, Choi E, Kim KW. Walkingspeed estimation using a single inertial measurement unit for the older adults. PLoS One. 2019. https://doi.org/10.1371/journal. pone. 0227075.

7. Campbell AJ, Robertson C. Comprehensive approach to fall prevention on a national level: New Zealand. Clin Geriatr Med. 2010;26(4):719-31. https://doi.org/10.1016/j.cger.2010.06.004.

8. Chapron K, Bouchard K, Gaboury S. Real-time gait speed evaluation at home. In: GoodTechs '19: proceedings of the 5th EAI 
international conference on smart objects and technologies for social good, 2019; pp. 55-60. https://doi.org/10.1145/3342428. 3342665.

9. Chen S, Lach J. Nonlinear feature for gait speed estimation using inertial sensors. In: BodyNets '13: proceedings of the 8th international conference on body area networks, 2013; pp. 185-188. https://doi.org/10.4108/icst.bodynets.2013.253737.

10. Chui K, Hood E, Klima D. Meaningful change in walking speed. Top Geriatr Rehabil. 2012;28(2):97-103. https://doi.org/10.1097/ TGR.0b013e3182510195.

11. Columbus: V-990 multifunction GPS data logger user manual 2011. https://cbgps.com/download/Columbus_V-990_User_ Manual_V1.0_ENG.pdf.

12. Cooper R, Kuh D, Cooper C, Gale CR, Lawlor DA, Matthews F, Hardy R, the FALCon Teams HS. Objective measures of physical capability and subsequent health: a systematic review. Age Ageing. 2011;40(1):14-23. https://doi.org/10.1093/ageing/afq117.

13. Croce UD, Cereatti A, Mancini M. Gait parameters estimated using inertial measurement units. 2018. https://doi.org/10.1007/ 978-3-319-14418-4_163.

14. Diekmann R, Hellmers S, Elgert L, Fudickar S, Heinks A, Lau S, Bauer JM, Zieschang T, Hein A. Minimizing comprehensive geriatric assessment to identify deterioration of physical performance in a healthy community-dwelling older cohort: longitudinal data of the aequipa versa study. Aging Clin Exp Res. 2020. https://doi. org/10.1007/s40520-020-01562-8.

15. Frenken T, Gövercin M, Mersmann S, Hein A. Precise assessment of self-selected gait velocity in domestic environments. 2010;1-8. https://doi.org/10.4108/ICST.PERVASIVEHEALTH2010.8829.

16. Frenken T, Steen EE, Brell M, Nebel W, Hein A. Motion pattern generation and recognition for mobility assessments in domestic environments. In: SciTePress, editors. Proceedings of the 1st international living usability lab workshop on AAL latest solutions, trends and applications. In conjunction with BIOSTEC 2011, 2011; pp. 3-12.

17. Fried LP, Tangen CM, Walston J, Newman AB, Hirsch C, Gottdiener J, Seeman T, Tracy R, Kop WJ, Burke G, McBurnie MA. Frailty in older adults: evidence for a phenotype. J Gerontol Ser A. 2001;56:M146-57. https://doi.org/10.1093/gerona/56.3.M146.

18. Giannouli E, Bock O, Mellone S, Zijlstra W. Mobility in old age: capacity is not performance. BioMed Res Int. 2016. https://doi. org/10.1155/2016/3261567.

19. Goffredo M, Bouchrika I, Carter JN, Nixon MS. Performance analysis for gait in camera networks. In: AREA '08: proceedings of the 1st ACM workshop on analysis and retrieval of events/ actions and workflows in video streams, 2008; pp. 73-80. https:// doi.org/10.1145/1463542.1463555.

20. Guralnik JM, Simonsick EM, Ferrucci L, Glynn RJ, Berkman LF, Blazer DG, Scherr PA, Wallace RB. A short physical performance battery assessing lower extremity function: association with selfreported disability and prediction of mortality and nursing home admission. J Gerontol. 1994;49:M85-94. https://doi.org/10.1093/ geronj/49.2.M85.

21. Hayes T, Hagler S, Austin D, Kaye J. Unobtrusive assessment of walking speed in the home using inexpensive PIR sensors. In: IEEE engineering in medicine and biology society, 2009; pp. 7248-7251. https://doi.org/10.1109/IEMBS.2009.5334746.

22. Hellmers S, Steen EE, Dasenbrock L, Heinks A, Bauer JM, Fudickar S, Hein A. Towards a minimized unsupervised technical assessment of physical performance in domestic environments. In: PervasiveHealth '17: proceedings of the 11th EAI international conference on pervasive computing technologies for healthcare, 2017; pp. 207-216. https://doi.org/10.1145/3154862.3154882.

23. Herdman M, Gudex C, Lloyd A, Janssen B, Kind P, Parkin D, Bonsel G, Badia X. Development and preliminary testing of the new five-level version of EQ-5D (EQ-5D-5L). Qual Life Res. 2011;20:1727-36. https://doi.org/10.1007/s11136-011-9903-X.

24. Hsu CY, Liu Y, Kabelac Z, Hristov R, Katabi D, Liu C. Extracting gait velocity and stride length from surrounding radio signals. In: CHI '17: proceedings of the $2017 \mathrm{CHI}$ conference on human factors in computing systems, 2017; pp. 2116-2126. https://doi. org/10.1145/3025453.3025937.

25. Kamnardsiri T, Khuwuthyakorn P, Boripuntakul S. The development of a gait speed detection system for older adults using video-based processing. In: ICBSP '19: proceedings of the 2019 4th international conference on biomedical imaging, signal processing, 2019; pp. 1-6. https://doi.org/10.1145/3366174.3366190.

26. Kumar N, Babu VR. Human gait recognition using depth camera: a covariance based approach. In: ICVGIP '12: proceedings of the eighth Indian conference on computer vision, graphics and image processing, 2012; pp. 1-6. https://doi.org/10.1145/2425333.24253 53.

27. Lawton MP, Brody EM. Assessment of older people: self-maintaining and instrumental activities of daily living. Gerontologist. 1969;9:179-86. https://doi.org/10.1093/geront/9.3_Part_1.179.

28. Majumder S, Aghayi E, Noferesti M, Memarzadeh-Tehran H, Mondal T, Pang Z, Deen MJ. Smart homes for elderly healthcarerecent advances and research challenges. Sensors. 2017;17(11). https://doi.org/10.3390/s17112496. https://www.mdpi.com/1424$8220 / 17 / 11 / 2496$

29. Majumder S, Mondal T, Deen MJ. Wearable sensors for remote health monitoring. Sensors. 2017;17(1). https://doi.org/10.3390/ s17010130. https://www.mdpi.com/1424-8220/17/1/130.

30. Marschollek M, Becker M, Bauer JM, Bente P, Elgert L, Elbers K, Hein A, Kolb G, Künemund H, Lammel-Polchau C, Meis M, Schwabedissen H, Remmers H, Schulze M, Steen EE, Thoben W, Wang J, Wolf KH, Haux R. Multimodal activity monitoring for home rehabilitation of geriatric fracture patients - feasibility and acceptance of sensor systems in the gal-natars study. Inform Health Soc Care. 2014;39:262-71. https://doi.org/10. 3109/17538157.2014.931852.

31. Middleton A, Fritz SL, Lusardi M. Walking speed: the functional vital sign. J Aging Phys Act. 2015;23(2):314-22. https:// doi.org/10.1123/japa.2013-0236.

32. Middleton A, Fulk GD, Beets MW, Herter TM, Fritz SL. Selfselected walking speed is predictive of daily ambulatory activity in older adults. J Aging Phys Act. 2016;24(2):214-22. https:// doi.org/10.1123/japa.2015-0104.

33. de Morton NA, Lane K. Validity and reliability of the de Morton Mobility Index in the subacute hospital setting in a geriatric evaluation and management population. J Rehabil Med. 2010;42(10):956-61. https://doi.org/10.2340/16501977-0626.

34. Motion SD. Shimmer3 wireless sensor platform. 2019. http:// www.shimmersensing.com/images/uploads/docs/Shimmer3 Spec_Sheet_V1.8.pdf.

35. Nadaraya EA. On non-parametric estimates of density functions and regression curves. Theory Probab Appl. 1965;10(1):18690. https://doi.org/10.1137/1110024.

36. von Ossietzky Universität Oldenburg C. Otago 2021. https:// uol.de/en/amt/research/projects/otago. Accessed $10 \mathrm{Jul} 2021$.

37. Pearson K. On lines and planes of closest fit to a system of points in space. Lond Edinb Dublin Philos Mag J Sci. 1901;6:559-72. https://doi.org/10.1080/14786440109462720.

38. Peel NM, Kuys SS, Klein K. Gait speed as a measure in geriatric assessment in clinical settings: a systematic review. J Gerontol Ser A. 2013;68(1):39-46. https://doi.org/10.1093/gerona/ gls174.

39. Phillips LJ, DeRoche CB, Rantz M, Alexander GL, Skubic M, Despins L, Abbott C, Harris BH, Galambos C, Koopman RJ. Using embedded sensors in independent living to predict gait 
changes and falls. West J Nurs Res. 2017;39(1):78-94. https:// doi.org/10.1177/0193945916662027.

40. Podsiadlo D, Richardson S. The timed "up \& go"': A test of basic functional mobility for frail elderly persons. J Am Geriatr Soc. 1991;32:142-8. https://doi.org/10.1111/j.1532-5415.1991. tb01616.x.

41. Rittweger J, Schiessl H, Felsenberg D, Runge M. Reproducibility of the jumping mechanography as a test of mechanical power output in physically competent adult and elderly subjects. J Am Geriatr Soc. 2004;52(1):128-31. https://doi.org/10.1111/j. 1532-5415.2004.52022.x.

42. Ryan RM, Deci EL. Self-determination theory and the facilitation of intrinsic motivation, social development, and well-being. Am Psychol. 2000;55(1):68-78. https://doi.org/10.1037/0003066X.55.1.68.

43. Searle SD, Mitnitski A, Gahbauer EA, Gill TM, Rockwood K. A standard procedure for creating a frailty index. BMC Geriatr. 2008. https://doi.org/10.1186/1471-2318-8-24.

44. Shuman V, Coyle PC, Perera S, VanSwearingen JM, Albert SM, Brach JS. Association between improved mobility and distal health outcomes. J Gerontol Ser A Biol Sci Med Sci. 2020. https://doi.org/10.1093/gerona/glaa086.

45. Silverman BW. Density estimation for statistics and data analysis. Boca Raton: CRC Press; 1986.

46. Stone E, Skubic M, Rantz M, Abbott C, Miller S. Average inhome gait speed: Investigation of a new metric for mobility and fall risk assessment of elders. Gait Posture. 2015;41(1):57-62. https://doi.org/10.1016/j.gaitpost.2014.08.019.

47. Studenski S, Perera S, Patel K, Rosano C, Faulkner K, Inzitari M, Brach J, Chandler J, Cawthon P, Connor EB, Nevitt M, Visser M, Kritchevsky S, Badinelli S, Harris T, Newman AB,
Cauley J, Ferrucci L, Guralnik J. Gait speed and survival in older adults. JAMA. 2011;305(1):50-8. https://doi.org/10.1001/ jama.2010.1923.

48. Tinetti ME. Performance-oriented assessment of mobility problems in elderly patients. J Am Geriatr Soc. 1986;34(2):119-26. https://doi.org/10.1111/j.1532-5415.1986.tb05480.x.

49. Troosters T, Gosselink R, Decramer M. Six minute walking distance in healthy elderly subjects. Eur Respir J. 1999;14(2):270-4. https://doi.org/10.1034/j.1399-3003.1999.14b06.x.

50. Vellas B, Guigoz Y, Garry PJ, Nourhashemi F, Bennahum D, Lauque S, Albarede JL. The Mini Nutritional Assessment (MNA) and its use in grading the nutritional state of elderly patients. Nutrition. 1999;15:116-22. https://doi.org/10.1016/S08999007(98)00171-3.

51. Washabaugh EP, Kalyanaraman T, Adamczyk peter G, Claflin ES, Krishnan C. Validity and repeatability of inertial measurement units for measuring gait parameters. Gait Posture. 2017;55:87-93. https://doi.org/10.1016/j.gaitpost.2017.04.013.

52. Yang S, Li Q. Inertial sensor-based methods in walking speed estimation: a systematic review. Sensors. 2012. https://doi.org/ 10.3390/s120506102.

53. Yeo SS, Park GY. Accuracy verification of spatio-temporal and kinematic parameters for gait using inertial measurement unit system. Sensors. 2020;20(5):1343. https://doi.org/10.3390/s2005 1343.

Publisher's Note Springer Nature remains neutral with regard to jurisdictional claims in published maps and institutional affiliations. 